\title{
Clinical characteristics and prognosis of elderly patients with colorectal cancer: comparison between surgical resection and supportive care
}

\section{Soohwan Kim}

Hallym University Sacred Heart Hospital

\section{Dong Suk Kim}

Hallym University Sacred Heart Hospital

Jae Seung Soh ( $\nabla$ jssoh@hanmail.net)

Hallym University Sacred Heart Hospital https://orcid.org/0000-0003-1594-6029

\section{Sang-Woo Lim}

Hallym University Sacred Heart Hospital

\section{Hyun Lim}

Hallym University Sacred Heart Hospital

\section{Ho Suk Kang}

Hallym University Sacred Heart Hospital

Jong Hyeok Kim

Hallym University Sacred Heart Hospital

\section{Research article}

Keywords: colorectal cancer, elderly, surgery, prognosis

Posted Date: March 20th, 2020

DOl: https://doi.org/10.21203/rs.3.rs-17903/v1

License: (c) (i) This work is licensed under a Creative Commons Attribution 4.0 International License.

Read Full License

Version of Record: A version of this preprint was published at Medicine on February 19th, 2021. See the published version at https://doi.org/10.1097/MD.0000000000024609. 


\section{Abstract}

Background Elderly colorectal cancer (CRC) patients tend to avoid standard treatment, especially curative surgical resection, because of concerns about surgical complications or underlying diseases. This study is intended to compare clinical characteristics and prognosis between patients who had undergone surgical resection and received supportive care, and to evaluate the usefulness of surgical treatment in elderly patients.

Methods A total of 114 patients aged $\geq 80$ years who were diagnosed with CRC were analyzed retrospectively. Of these patients, 73 patients underwent surgical resection for malignancy and 41 patients received supportive care. Clinicopathological factors and overall survival (OS) rates were compared.

Results The s urgical resection group had better Eastern Cooperative Oncology Group (ECOG) performance status, American Society of Anesthesiologists (ASA) physical status, and a lower stage than did the supportive-care group. The 3-year OS rate of the surgical group was significantly higher than that of the supportive-care group ( $60.7 \%$ vs. $9.1 \%, p<0.001)$. In extremely elderly patients (age $\geq 85$ years), the surgical group showed a better 3-year OS rate than did the supportive-care group $(73.9 \%$ vs. $6.3 \%, p<$ 0.001), although ECOG performance status and ASA physical status were not different. The postoperative mortality rate was $4.1 \%$. In the analysis of risk factors related to survival, surgical resection was a good prognostic factor.

Conclusions Surgical treatment in elderly CRC patients showed a survival benefit, even in the extremely elderly patients. Surgical resection for CRC in elderly patients can be considered to improve survival.

\section{Background}

Colorectal cancer (CRC) is the third most commonly diagnosed malignancy and second leading cause of cancer death in the world. Elderly people have a higher incidence and mortality rate of CRC than do younger people. With the aging population, around $20 \%$ of patients diagnosed with CRC are more than 80 years old in the United States $[1,2]$.

Elderly patients tend to avoid standard treatment, including curative resection of malignancy, because of the concerns about surgical complications and comorbidities, and go through supportive or palliative care rather than active treatment for cancer. As a result, a large proportion of elderly patients with CRC may receive sub-standard treatment [3]. However, studies found that survival of elderly patients who receive anticancer treatment including surgery or chemotherapy could be meaningfully improved more than that of those who received only supportive care $[4,5]$.

CRC presents with many complications, including obstruction, bleeding, and perforation at the diagnosis, and surgery plays a major role in treating CRC. Recent advances in technology, skills, and studies have made it possible for elderly patients to undergo surgical treatment relatively safely. It has been found that 
surgical resection of CRC can be tolerated well, especially if done laparoscopically in elderly patients [6, 7]. Therefore, decisions about surgical resection for elderly CRC patients should consider various conditions of the patients besides age.

Our aim in this study is to compare clinical characteristics and prognosis between patients aged $\geq$ 80 years who had undergone surgical resection and received supportive care, and to evaluate the usefulness of surgical treatment in elderly patients. We also did prognostic analysis related to survival in elderly patients with CRC.

\section{Methods}

\section{Study population}

Between March 2007 and November 2017, a total of 125 patients aged $\geq 80$ years old were diagnosed with colorectal adenocarcinoma at the Hallym University Sacred Heart Hospital in Anyang, Korea. We reviewed these patients retrospectively and classified them according to treatment modalities and age. Of the 125 patients, 11 were excluded for resecting with endoscopic submucosal dissection or endoscopic mucosal resection (4 patients), transfer to another hospital after the diagnosis of cancer (4 patients), and no available clinical information, including treatment and outcome for analysis (3 patients). A total of 114 patients were included in our study. Of these patients, 44 were more than 85 years old, and they were defined as the extremely elderly group. Clinical, pathological, and outcome data were collected by reviewing patient medical records and by interviewing patients by phone. The local ethics committee at Hallym Sacred Heart Medical Center approved the use of clinical data for this study (IRB 2018-09-011).

\section{Clinicopathological data}

The following patients characteristics were analyzed: age, sex, comorbidity disease, body mass index (BMI), hemoglobin and carcinoembryonic antigen (CEA) level, performance status (Eastern Cooperative Oncology Group [ECOG]) at initial diagnosis [8], American Society of Anesthesiologists (ASA) classification [9], tumor location, clinical stage, lymph-node metastasis, tumor size, histological type, perforation, therapeutic modalities, and treatment outcomes. BMI was calculated as weight $(\mathrm{kg})$ divided by height squared $\left(\mathrm{m}^{2}\right)$ at initial diagnosis. Comorbidity diseases were defined as follows: (1) cardiovascular disease included patients with coronary artery disease (myocardial infarction, angina) and heart failure; (2) cerebral disease included patients with a history of a cerebrovascular accident and transient ischemic attacks; (3) pulmonary disease included patients with asthma, chronic bronchitis, emphysema, and other chronic lung disease; (4) renal disease included chronic kidney disease.

Tumor location was divided into right side of the colon (including cecum, ascending colon, and transverse colon) and left side of the colon (including descending colon, sigmoid colon, and rectum). Preoperative clinical staging was established by enhanced computed tomography (CT). The long diameter of an enlarged lymph node greater than $0.8 \mathrm{~cm}$ on CT image was defined as lymph-node metastasis. Distant metastasis was defined as the cancer spreading to organs or lymph nodes far away from the colon. The 
differentiation of tumor was evaluated according to the percentage portion of the tumor exhibiting glandular structures between differentiated (well and moderately differentiated adenocarcinoma) and undifferentiated (poorly differentiated adenocarcinoma, signet-ring cell carcinoma, and mucinous adenocarcinoma). Post-operative mortality was defined as being within 30 days of surgery.

\section{Statistical analyses}

Baseline characteristics and clinical outcomes were compared between the surgery group and the supportive-care group. Continuous variables were compared by Student t-tests, and categorical variables were compared with chi-square tests or Fisher's exact tests. All $p<0.05$ were considered to be statistically significant. We did a survival analysis using Kaplan-Meier curves and compared these using the log-rank test by a Cox regression analysis. The overall survival (OS) was defined as the time from the date of diagnosis to the date of death. We used the SPSS software (version 22.0; SPSS, Chicago, IL, USA) for all statistical analyses.

\section{Results}

\section{Baseline characteristics of the patients according to the treatment modality}

Of the 114 patients with CRC, 73 had surgical resection and/or postoperative chemotherapy for malignancy (surgery group) and 41 had supportive care without surgical resection, chemotherapy, or radiation therapy (supportive-care group). Among the 41 patients in the supportive-care group, six patients had bypass surgery without resection of cancer lesions. Baseline characteristics of the patients according to the treatment modality are shown in Table 1 . The surgery group was younger than the supportive-care group $(p=0.028)$. The supportive-care group showed higher ECOG performance status, ASA grade, clinical stage, and more lymph node metastasis $(p=0.009,0.001,0.001$, and 0.002 , respectively). 
Table 1

Baseline characteristics of the patients according to the treatment modality

\begin{tabular}{|c|c|c|c|}
\hline & Surgery & Supportive-care & P-value \\
\hline & $(n=73)$ & $(n=41)$ & \\
\hline Age, mean, years (range) & $83.6(80-94)$ & $85.0(80-94)$ & 0.028 \\
\hline Male sex, no. (\%) & $29(39.7)$ & $14(34.1)$ & 0.688 \\
\hline \multicolumn{4}{|l|}{ Comorbidity } \\
\hline HTN, no. (\%) & $47(64.4)$ & $23(56.1)$ & 0.426 \\
\hline DM, no. (\%) & $20(27.4)$ & $9(22.0)$ & 0.655 \\
\hline Cardiovascular disease, no. (\%) & $9(12.3)$ & $9(22.0)$ & 0.191 \\
\hline Cerebral disease, no. (\%) & $18(24.7)$ & $11(26.8)$ & 0.825 \\
\hline Pulmonary disease, no. (\%) & $4(5.5)$ & $6(14.6)$ & 0.164 \\
\hline Renal disease, no. (\%) & $3(4.1)$ & $3(7.3)$ & 0.665 \\
\hline Other malignancy, no. (\%) & $5(6.8)$ & $4(9.8)$ & 0.720 \\
\hline BMI, mean, kg/m² (range) & $22.8(15.9-30.2)$ & $21.6(14.2-29.7)$ & 0.065 \\
\hline Hemoglobin, mean, g/dL (range) & $10.8(5.4-17.3)$ & $10.2(4.0-14.8)$ & 0.225 \\
\hline CEA $\geq 5$ ng/mL, no. (\%) & $29(39.7)$ & $24(58.5)$ & 0.078 \\
\hline Performance (ECOG) status & & & 0.009 \\
\hline $0-2$, no. $(\%)$ & $51(69.9)$ & $18(43.9)$ & \\
\hline $3-4$, no. $(\%)$ & $22(30.1)$ & $23(56.1)$ & \\
\hline ASA grade & & & $<0.001$ \\
\hline I, II, no. (\%) & $38(52.1)$ & 5 (12.2) & \\
\hline III, IV, no. (\%) & 35 (47.9) & $36(87.8)$ & \\
\hline Location of tumor & & & 0.560 \\
\hline Right colon, no. (\%) & $36(49.3)$ & $23(56.1)$ & \\
\hline Left colon, no. (\%) & $47(50.7)$ & $18(43.9)$ & \\
\hline Clinical stage & & & $<0.001$ \\
\hline I, no. (\%) & $9(12.3)$ & $3(7.3)$ & \\
\hline
\end{tabular}




\begin{tabular}{|llll|}
\hline & Surgery & Supportive-care & P-value \\
\hline II, no. (\%) & $33(45.2)$ & $6(14.6)$ & \\
\hline III, no. (\%) & $23(31.5)$ & $10(24.4)$ & \\
\hline IV, no. (\%) & $8(11.0)$ & $22(53.7)$ & 0.002 \\
\hline Lymph node metastasis, no. (\%) & $30(41.1)$ & $30(73.2)$ & 0.195 \\
\hline Tumor size, mean, cm (range) & $4.7(1.0-12.7)$ & $5.3(2.0-12.7)$ & 0.087 \\
\hline Histologic type & & & \\
\hline Differentiated & $68(93.2)$ & $26(81.3)$ & 0.163 \\
\hline Undifferentiated & $5(6.8)$ & $6(18.8)$ & \\
\hline Perforation, no. (\%) & 13 (17.8) & $3(7.3)$ & \\
\hline $\begin{array}{l}\text { HTN, hypertension; DM, diabetes mellitus; BMI, body mass index; ECOG, Eastern Cooperative } \\
\text { Oncologic Group; ASA, American Society of Anesthesiologists }\end{array}$ & \\
\hline
\end{tabular}

\section{Prognostic analyses for overall survival in the patients}

Forty-two patients died in the surgery group (57.5\%) compared to 37 patients $(90.2 \%)$ in the supportivecare group during the follow-up period. The mean follow-up period was 28 months, ranging from 1 to 121 months. Figure 1 shows the OS curves of the patients according to the treatment modality using Kaplan-Meier estimation. The OS rate of the surgery group was significantly higher than that of the supportive-care group $(\mathrm{p}<0.001)$. The 3-year OS rates of the surgery and supportive-care groups were $60.7 \%$ and $9.1 \%$, respectively. The post-operative mortality rate of the surgery group was $2.7 \%(2 / 73)$.

Prognostic factors related to the OS were investigated by univariate and multivariate analysis (Table 2). CEA $\geq 5 \mathrm{ng} / \mathrm{mL}(p=0.012)$, ASA grade $(p=0.017)$, lymph-node metastasis $(p=0.001)$, tumor size $(p=$ $0.026)$, and surgical treatment modality $(p=0.001)$ had a statistically significant association with overall survival by univariate analysis. However, only the surgical treatment modality was associated with better overall survival in multivariate analysis. (hazard ratio $[H R]=0.235 ; p=0.019$ ). 
Table 2

Univariate and multivariate analyses of risk factors for overall survival

\begin{tabular}{|c|c|c|c|c|c|c|}
\hline & \multicolumn{3}{|c|}{ Univariate analysis } & \multicolumn{3}{|c|}{ Multivariate analysis } \\
\hline & $\mathrm{HR}$ & $95 \% \mathrm{Cl}$ & P-value & $H R$ & $95 \% \mathrm{Cl}$ & P-value \\
\hline Age, 1-year increase & 1.050 & $0.926-1.190$ & 0.449 & & & \\
\hline Male sex & 0.808 & $0.352-1.855$ & 0.615 & & & \\
\hline \multicolumn{7}{|l|}{ Comorbidity } \\
\hline HTN & 0.435 & $0.181-1047$ & 0.063 & & & \\
\hline DM & 0.979 & $0.393-2.438$ & 0.964 & & & \\
\hline Cardiovascular disease & 1.669 & $0.507-5.491$ & 0.399 & & & \\
\hline Cerebral disease & 1.222 & $0.480-3.108$ & 0.674 & & & \\
\hline Pulmonary disease & 1.859 & $0.374-9.241$ & 0.448 & & & \\
\hline Renal disease & 2.297 & $0.258-20.426$ & 0.456 & & & \\
\hline Other malignancy & 3.831 & $0.460-31.874$ & 0.214 & & & \\
\hline $\mathrm{BMI} \geq 25 \mathrm{~kg} / \mathrm{m}^{2}$ & 0.979 & $0.393-2.438$ & 0.964 & & & \\
\hline Hemoglobin $\geq 8 \mathrm{~g} / \mathrm{dL}$ & 0.632 & $0.120-3.329$ & 0.632 & & & \\
\hline $\mathrm{CEA} \geq 5 \mathrm{ng} / \mathrm{mL}$ & 2.986 & $1.268-7.033$ & 0.012 & 2.155 & $0.840-5.534$ & 0.110 \\
\hline \multicolumn{7}{|l|}{ Performance (ECOG) status } \\
\hline $0-2$ & 1 & & & & & \\
\hline $3-4$ & 1.989 & $0.844-4.687$ & 0.116 & & & \\
\hline \multicolumn{7}{|l|}{ ASA grade } \\
\hline I, II & 1 & & & & & \\
\hline III, IV & 2.721 & $1.199-6.178$ & 0.017 & 1.260 & $0.496-3.203$ & 0.627 \\
\hline \multicolumn{7}{|l|}{ Location of tumor } \\
\hline Right colon & 1 & & & & & \\
\hline Left colon & 1.158 & $0.521-2.572$ & 0.719 & & & \\
\hline Lymph node metastasis & 4.310 & $1.816-10.230$ & 0.001 & 2.439 & $0.900-6.613$ & 0.080 \\
\hline Tumor size, $1 \mathrm{~cm}$ increase & 1.304 & $1.032-1.647$ & 0.026 & 1.137 & $0.877-1.474$ & 0.333 \\
\hline
\end{tabular}




\begin{tabular}{|c|c|c|c|c|c|c|}
\hline & \multicolumn{3}{|c|}{ Univariate analysis } & \multicolumn{3}{|c|}{ Multivariate analysis } \\
\hline \multicolumn{7}{|l|}{ Histologic type } \\
\hline Differentiated & 1 & & & & & \\
\hline Undifferentiated & 1.312 & $0.325-5.294$ & 0.703 & & & \\
\hline Perforation & 0.700 & $0.233-2.107$ & 0.526 & & & \\
\hline \multicolumn{7}{|c|}{ Treatment modality } \\
\hline Supportive-care & 1 & & & & & \\
\hline Surgery & 0.146 & $0.047-0.454$ & 0.001 & 0.235 & $0.070-0.789$ & 0.019 \\
\hline \multicolumn{7}{|c|}{$\begin{array}{l}\text { HR, hazard ratio; } \mathrm{Cl} \text {, confidence interval; } \mathrm{HTN} \text {, hypertension; DM, diabetes mellitus; BMI, body mass } \\
\text { index; ECOG, Eastern Cooperative Oncologic Group; ASA, American Society of Anesthesiologists }\end{array}$} \\
\hline
\end{tabular}

Of 44 patients aged $\geq 85$ years, 23 patients had surgical resection and/or chemotherapy of malignancy and 21 patients received supportive care. Table 3 shows the baseline characteristics of the extremely elderly group according to the treatment modality. There were no significant differences between the surgery group and supportive-care group including CEA level, ECOG performance status, ASA grade, and lymph-node metastasis. The surgery group showed a lower than did the supportive-care group $(p<0.001)$. 
Table 3

Baseline characteristics of the extremely elderly group according to the treatment modality

\begin{tabular}{|c|c|c|c|}
\hline & Surgery & Supportive-care & P-value \\
\hline & $(n=23)$ & $(n=21)$ & \\
\hline Age, mean, years (range) & $87.5(85-94)$ & $87.7(85-94)$ & 0.791 \\
\hline Male sex, no. (\%) & $7(30.4)$ & $6(28.6)$ & 1.000 \\
\hline \multicolumn{4}{|l|}{ Comorbidity } \\
\hline HTN, no. (\%) & $19(82.6)$ & $11(52.4)$ & 0.052 \\
\hline DM, no. (\%) & $5(21.7)$ & $3(14.3)$ & 0.701 \\
\hline Cardiovascular disease, no. (\%) & $2(8.7)$ & $5(23.8)$ & 0.232 \\
\hline Cerebral disease, no. (\%) & $5(21.7)$ & $2(9.5)$ & 0.416 \\
\hline Pulmonary disease, no. (\%) & $2(8.7)$ & $2(9.5)$ & 1.000 \\
\hline Renal disease, no. (\%) & $1(4.3)$ & $1(4.8)$ & 1.000 \\
\hline Other malignancy, no. (\%) & $3(13.0)$ & $1(4.8)$ & 0.609 \\
\hline BMI, mean, $\mathrm{kg} / \mathrm{m}^{2}$ (range) & $23.1(16.6-30.2)$ & $21.5(15.2-29.3)$ & 0.178 \\
\hline Hemoglobin, mean, g/dL (range) & $10.6(6.1-15.1)$ & $9.9(6.1-14.8)$ & 0.420 \\
\hline CEA $\geq 5$ ng/mL, no. (\%) & $9(39.1)$ & $12(57.1)$ & 0.365 \\
\hline Performance (ECOG) status & & & 1.000 \\
\hline $0-2$, no. $(\%)$ & $13(56.5)$ & $11(52.4)$ & \\
\hline $3-4$, no. $(\%)$ & $10(43.5)$ & $10(47.6)$ & \\
\hline ASA grade & & & 0.462 \\
\hline I,II, no. (\%) & $6(26.1)$ & $3(14.3)$ & \\
\hline III, IV, no. (\%) & $17(73.9)$ & $18(85.7)$ & \\
\hline Location of tumor & & & 0.533 \\
\hline Right colon, no. (\%) & $16(69.6)$ & $12(57.1)$ & \\
\hline Left colon, no. (\%) & $7(30.4)$ & $9(42.9)$ & \\
\hline Clinical stage & & & $<0.001$ \\
\hline I, no. (\%) & $2(8.4)$ & $1(4.8)$ & \\
\hline
\end{tabular}




\begin{tabular}{|llll|}
\hline & Surgery & Supportive-care & P-value \\
\hline II, no. (\%) & $12(52.2)$ & $4(19.0)$ & \\
\hline III, no. (\%) & $7(30.4)$ & $2(9.5)$ & \\
\hline IV, no. (\%) & $2(8.7)$ & $14(66.7)$ & 0.080 \\
\hline Lymph node metastasis, no. (\%) & $9(39.1)$ & $14(66.7)$ & 0.321 \\
\hline Tumor size, mean, cm (range) & $4.5(2.0-8.0)$ & $5.1(2.5-12.7)$ & 0.348 \\
\hline Perforation, no. (\%) & $4(17.4)$ & $1(4.8)$ & \\
\hline $\begin{array}{l}\text { HTN, hypertension; DM, diabetes mellitus; BMI, body mass index; ECOG, Eastern Cooperative } \\
\text { Oncologic Group; ASA, American Society of Anesthesiologists }\end{array}$ & & \\
\hline
\end{tabular}

\section{Prognostic analyses for overall survival in the extremely elderly group}

During the mean follow-up of 23 months (range, 1-96 months), 11 patients expired in the surgery group $(47.8 \%)$ and 19 patients $(90.5 \%)$ died in the supportive-care group. The OS curves showed that the surgery group had a higher OS rate than did the supportive-care group (Fig. 2; $p<0.001$ ). The 3-year OS rate of the surgery group was $73.9 \%$ and that of the supportive-care group was $6.3 \%$. The post-operative mortality rate was $4.3 \%(1 / 23)$.

The risk factors associated with OS in the extremely elderly group are indicated in Table 4. In the univariate analysis, CEA $\geq 5 \mathrm{ng} / \mathrm{mL}(p=0.023)$, lymph-node metastasis $(p=0.037)$, and surgical treatment modality $(p=0.006)$ showed a statistical significance. In multivariate analysis, surgical treatment modality was associated with better overall survival $(H R=0.083 ; p=0.009)$ and CEA $\geq 5 \mathrm{ng} / \mathrm{mL}$ was inversely related to good overall survival $(H R=5.635 ; p=0.039)$. 
Table 4

Univariate and multivariate analyses of risk factors for overall survival in the extremely elderly group

Univariate analysis

Multivariate analysis

$\mathrm{HR} \quad 95 \% \mathrm{Cl}$

P. $\quad$ HR $\quad 95 \% \mathrm{Cl}$

value

P-value

Age, 1-year increase

1.317

$0.927-1.871$

0.124

Male sex

1.833

0.415-8.096

0.424

Comorbidity

HTN

$0.614 \quad 0.211-1.785 \quad 0.370$

DM

$\begin{array}{lll}0.385 & 0.080-1.841 & 0.232\end{array}$

Cardiovascular disease

1.200

$0.203-7.105$

0.841

Cerebral disease

0.278

$0.053-1.466$

0.131

Pulmonary disease

$1.444 \quad 0.137-$

0.760

15.266

Renal disease

0.448

$0.026-7.734$

0.581

Other malignancy

1.444

$0.137-$

15.266

$\mathrm{BMI} \geq 25 \mathrm{~kg} / \mathrm{m}^{2}$

0.450

0.110-1.848

0.760

Hemoglobin $\geq 8 \mathrm{~g} / \mathrm{dL}$

0.389

$0.072-2.104$

0.273

$\mathrm{CEA} \geq 5 \mathrm{ng} / \mathrm{mL}$

$5.500 \quad 1.264-$

0.023

5.635

1.089

29.166

0.039

Performance (ECOG)

status

0-2

1

3-4

1.167

$0.325-4.190$

0.813

ASA grade

I, II

1

III, IV

2.000

$0.444-9.013$

0.367

Location of tumor

Right colon

1

$\mathrm{HR}$, hazard ratio; $\mathrm{Cl}$, confidence interval; $\mathrm{HTN}$, hypertension; $\mathrm{DM}$, diabetes mellitus; $\mathrm{BMI}$, body mass index; ECOG, Eastern Cooperative Oncologic Group; ASA, American Society of Anesthesiologists 


\begin{tabular}{|c|c|c|c|c|c|c|}
\hline \multirow[b]{2}{*}{ Left colon } & \multicolumn{2}{|c|}{ Univariate analysis } & \multicolumn{3}{|c|}{ Multivariate analysis } & \\
\hline & 1.667 & $0.423-6.562$ & 0.465 & & & \\
\hline Lymph node metastasis & 4.318 & $1.090-17.112$ & 0.037 & 0.837 & $0.572-1.227$ & 0.363 \\
\hline Tumor size, $1 \mathrm{~cm}$ increase & 0.973 & $0.690-1.373$ & 0.876 & & & \\
\hline \multicolumn{7}{|l|}{ Histologic type } \\
\hline Differentiated & 1 & & & & & \\
\hline Undifferentiated & 2.182 & $\begin{array}{l}0.218- \\
21.793\end{array}$ & 0.506 & & & \\
\hline Perforation & 0.262 & $0.038-1.787$ & 0.171 & & & \\
\hline \multicolumn{7}{|l|}{ Treatment modality } \\
\hline Supportive-care & 1 & & & & & \\
\hline Surgery & 0.096 & $0.018-0.513$ & 0.006 & 0.083 & $0.013-0.536$ & 0.009 \\
\hline
\end{tabular}

\section{Pathology of the surgery group}

Table 5 shows the operation methods and pathology of the surgery group. Thirty-five patients received anterior resection or the Hartmann operation and 30 patients had a right hemicolectomy. One patient received a right hemicolectomy and anterior resection for treating two malignant lesions simultaneously. Pathological stage III was most common (74.0\%), and lymph-node invasion was detected in 31 patients (42.5\%). Of eight patients with metastasis (4 patients with liver metastasis, 2 patients with liver and lung metastasis, and 2 patients with paraaortic lymph-node metastasis), six patients were given a palliative surgical resection for obstruction. The other two patients with liver metastasis were given bowel resection with hepatectomy for curative surgical treatments. The mean size of tumors was $5.2 \mathrm{~cm}$, and poorly differentiated malignancy was $6.8 \%$. Lymphatic, vascular, and perineural invasions of the pathological specimens were $37.0 \%, 17.8 \%$, and $19.2 \%$, respectively. Postoperative chemotherapy was done in 15 patients $(20.5 \%)$, and recurrence was detected in 12 patients during the follow-up periods. 
Table 5

Pathology of the surgery group

\begin{tabular}{|ll|}
\hline & Surgery group \\
\hline & $(\mathrm{n}=73)$ \\
\hline Operation method & $35(47.9)$ \\
\hline Anterior resection or Hartmann, no. (\%) & $30(41.1)$ \\
\hline Right hemicolectomy, no. (\%) & $5(6.8)$ \\
\hline Left hemicolectomy, no. (\%) & $1(1.4)$ \\
\hline Right hemicolectomy + anterior resection, no. (\%) & $1(1.4)$ \\
\hline Transverse colectomy, no. (\%) & $1(1.4)$ \\
\hline Cecectomy, no. (\%) & \\
\hline pT stage & $4(5.5)$ \\
\hline I, no. (\%) & $10(13.7)$ \\
\hline II, no. (\%) & $54(74.0)$ \\
\hline III, no. (\%) & $5(6.8)$ \\
\hline IV, no. (\%) & $22(30.1)$ \\
\hline pN stage & $46(63.1)$ \\
\hline 0, no. (\%) & $5(6.8)$ \\
\hline I, no. (\%) & $22(25.0)$ \\
\hline II, no. (\%) & $9(12.3)$ \\
\hline Surgical method in patients with stage IV & \\
\hline Anterior resection or Hartmann, palliative, no. (\%) & $4(1.0-17.0)$ \\
\hline Right hemicolectomy, palliative, no. (\%) & \\
\hline Anterior resection + hepatectomy, no. (\%) & \\
\hline Tumor size, mean, cm (range) & \\
\hline Histologic type & \\
\hline Well differentiated, no. (\%) & \\
\hline Moderately differentiated, no. (\%) & \\
\hline Poorly differentiated, no. (\%) & \\
\hline
\end{tabular}




\begin{tabular}{|ll|}
\hline & Surgery group \\
\hline Lymphatic invasion, no. (\%) & $27(37.0)$ \\
\hline Vascular invasion, no. (\%) & $13(17.8)$ \\
\hline Perineural invasion, no. (\%) & $14(19.2)$ \\
\hline Postoperative chemotherapy, no. (\%) & $15(20.5)$ \\
\hline Recurrence, no. (\%) & $12(16.4)$ \\
\hline
\end{tabular}

\section{Discussion}

The number of elderly patients with CRC is expected to rise, especially in developed countries with an aging society, and it is strongly correlated with affluent lifestyles, such as increased meat consumption, and obesity [2]. Because the CRC incidence rate is much higher in the elderly population, a proper treatment modality for CRC patients of advanced age is critical in an aging society. Poor performance status, higher incidence of comorbidities, and lower life expectancy of elderly patients lead them to decline sufficient treatment, such as radical surgery, and can lead to less optimal treatment. However, surgical treatment is still the first choice even in CRC patients of advanced age. Our results showed that patients aged $\geq 80$ years benefit in survival from surgical resection. In addition, extremely elderly CRC patients aged $\geq 85$ years showed a survival benefit in the surgery group, despite having performance and ASA status similar to that of the supportive-care group.

Published data on the treatment of elderly patients with CRC are limited. Several studies showed favorable results for surgery in elderly CRC patients. Surgical resection of CRC can lead to a complete cure, especially in localized disease and better survival even in selected metastatic diseases $[5,10]$. Tolerability of surgery by elderly patients aged $\geq 80$ years has been investigated in several studies and showed favorable outcomes in terms of postoperative mortality as compared with that of younger patients [11-13]. When "elderly" was defined as $\geq 75$ years, the cancer-specific survival rate of elderly CRC patients receiving surgical treatment was not significantly different from that of younger patients [14-16]. However, a few studies showed that emergency operations were more common in elderly CRC patients; therefore, they had more complications and post-operative mortality than did younger patients $[14,17,18]$. Because of a higher risk of treatment-related complications, elderly CRC patients have shown a poorer prognosis than have young CRC patients [19].

A previous study from our hospital compared the survival rates of the surgery group with those of the supportive-care group in elderly patents aged $\geq 80$ years with advanced gastric cancer [20]. This study showed that patients aged 80-85 years could expect a better prognosis with surgical resection, and surgical resection in extremely elderly patients aged $\geq 85$ years also tended to be associated good prognosis, although there was no statistical significance. In this study, we found that the surgical treatment modality in CRC patients was significantly associated with better OS in both the elderly and the 
extremely elderly groups. The post-operative mortality rates for gastric cancer and CRC in our institution were $6.1 \%(3 / 49)$ and $2.7 \%(2 / 73)$, respectively; that showed relatively low morbidity after surgical treatment. With these results, cancer surgery could be considered positively for patients aged $\geq 80$ years.

One important prognostic factor in deciding on operability for elderly patients with CRC was performance status. The surgery group had more patients with good performance status than did the supportive-care group (ECOG performance status $0-2 ; 69.9 \%$ vs. $54.9 \%, p=0.009$ ). However, performance status was not a significant prognostic factor for OS in our study. Performance status was subjective and might be different according to physicians. In addition, patients with good performance status often refused surgical resection considering their advanced age and comorbidities by themselves or their families. In the supportive-care group, patients with good performance status had longer mean survival than did patients with poor performance status, although it did not reach statistical significance (12.9 months vs. 5.7 months, $p=0.078$ ). Another factor in deciding on operability was clinical stage at the diagnosis of CRC. More patients were clinical stage IV in the supportive-care group than in the surgery group (53.7\% vs. $11.0 \%, p<0.001$ ). Among eight patients with metastatic disease in the surgery group, two had radical surgery, including hepatectomy, and the other six patients had palliative surgery. However, the mean survival durations of surgery patients with metastatic disease were not different from those of the supportive-care group ( 12.5 months vs. 8.9 months, $p=0.450$ ). Although surgery was associated with better OS, elderly patients should decide on the treatment modality considering their own conditions and disease status.

Except for performance status and clinical stage, treatment of elderly patients with CRC was decided by considering various factors, such as comorbidities, CEA level, lymph-node involvement, tumor location, tumor size, and histologic differentiation. In this study, CEA $\geq 5 \mathrm{ng} / \mathrm{mL}$, ASA grade, lymph-node metastasis, and tumor size were risk factors correlated with OS in the univariate analysis. Detailed examination of the various clinicopathological factors presented in the diagnosis is important for deciding on the treatment modality in elderly patients with CRC. A multidisciplinary team approach has been increasingly used, and a comprehensive geriatric assessment can be helpful in identifying patients who can tolerate surgery without significant complications [21,22]. Only after considering risks and benefits of surgery should surgical resection be done in elderly CRC patients.

Our study had several limitations. First, the analysis was retrospective and was a small study conducted in a single center. There may be unrecognized or unmeasured biases. Second, background factors including performance status, ASA grade, and clinical stage were different between the two groups, which might have influenced the prognosis in the analysis, and the supportive-care group cannot be clearly considered to be a control group for the surgery group. Third, disease-specific survival rate was not shown in this study. Because all patients were advanced in age, investigating specific causes of death was impossible.

\section{Conclusions}


Our results showed that elderly patients with $\mathrm{CRC}$ had a survival benefit from surgical resection. In the extremely elderly patients aged $\geq 85$ years, surgery was associated with a better OS rate than the supportive care had, although the two groups had a similar performance status and ASA grade. Surgical resection for $\mathrm{CRC}$ in elderly patients can be done to improve their survival rate after considering various clinicopathologic factors of patients.

\section{Abbreviations}

ASA

American Society of Anesthesiologists; BMI:body mass index; CEA:carcinoembryonic antigen; Cl:confidence interval; CRC:colorectal cancer; CT:computed tomography; DM:diabetes mellitus; ECOG:Eastern Cooperative Oncology Group; HR:hazard ratio; HTN:hypertension; OS:overall survival;

\section{Declarations}

Ethics approval and consent to participate. The local ethics committee at Hallym Sacred Heart Medical Center approved the use of clinical data for this study (IRB No. 2018-09-011). All study participants provided written informed consent prior to enrollment.

Consent for publication: Not applicable

Availability of data and materials. The datasets used and/or analyzed during the current study are available from the corresponding author on reasonable request.

Competing interests. The authors declare that they have no competing interests.

Funding. This research was supported by the Hallym University Research Fund (HURF-2018-06) and the National Research Foundation of Korea (NRF) grant funded by the Korean government (MSIP; Ministry of Science, ICT \& Future Planning) (No. NRF-2018R1C1B5083260).

Author contributions. JSS and SK designed the study and wrote the manuscript; JSS and DSK recruited the participants and interpreted the data; JSS, SWL, HL, HSK, and JHK analyzed and interpreted the data, and revised the manuscript. All authors have read and approved the manuscript. 
Acknowledgements: None

\section{Author details}

${ }^{1}$ Department of Internal Medicine, University of Hallym College of Medicine, Hallym University Sacred Heart Hospital, Anyang, Republic of Korea

${ }^{2}$ Department of Colorectal Surgery, University of Hallym College of Medicine, Hallym University Sacred Heart Hospital, Anyang, Republic of Korea

\section{References}

1. Siegel RL, Miller KD, Fedewa SA, Ahnen DJ, Meester RGS, Barzi A, et al. Colorectal cancer statistics, 2017. CA: a cancer journal for clinicians. 2017;67(3):177-93.

2. Douaiher J, Ravipati A, Grams B, Chowdhury S, Alatise O, Are C. Colorectal cancer-global burden, trends, and geographical variations. Journal of surgical oncology. 2017;115(5):619-30.

3. Aparicio T, Navazesh A, Boutron I, Bouarioua N, Chosidow D, Mion M, et al. Half of elderly patients routinely treated for colorectal cancer receive a sub-standard treatment. Critical reviews in oncology/hematology. 2009;71(3):249-57.

4. Jung YH, Kim JY, Jang YN, Yoo SH, Kim GH, Lee KM, et al. Clinical characteristics and treatment propensity in elderly patients aged over 80 years with colorectal cancer. The Korean journal of internal medicine. 2018;33(6):1182-93.

5. Grande R, Natoli C, Ciancola F, Gemma D, Pellegrino A, Pavese I, et al. Treatment of Metastatic Colorectal Cancer Patients $>/=75$ Years Old in Clinical Practice: A Multicenter Analysis. PloS one. 2016;11(7):e0157751.

6. Frasson M, Braga M, Vignali A, Zuliani W, Di Carlo V. Benefits of laparoscopic colorectal resection are more pronounced in elderly patients. Diseases of the colon and rectum. 2008;51(3):296-300.

7. Chautard J, Alves A, Zalinski S, Bretagnol F, Valleur P, Panis Y. Laparoscopic colorectal surgery in elderly patients: a matched case-control study in 178 patients. Journal of the American College of Surgeons. 2008;206(2):255-60.

8. Oken MM, Creech RH, Tormey DC, Horton J, Davis TE, McFadden ET, et al. Toxicity and response criteria of the Eastern Cooperative Oncology Group. American journal of clinical oncology. 1982;5(6):649-55.

9. Practice guidelines for sedation and analgesia by non-anesthesiologists. Anesthesiology. 2002;96(4):1004-17. 
10. Morris EJ, Forman D, Thomas JD, Quirke P, Taylor EF, Fairley L, et al. Surgical management and outcomes of colorectal cancer liver metastases. The British journal of surgery. 2010;97(7):1110-8.

11. Devoto L, Celentano V, Cohen R, Khan J, Chand M. Colorectal cancer surgery in the very elderly patient: a systematic review of laparoscopic versus open colorectal resection. International journal of colorectal disease. 2017;32(9):1237-42.

12. Tabbakh Y, Ihedioha U, Panteleimonitis S, Gevech Z, Evans J, Kang P. Laparoscopic colorectal surgery: Is it beneficial in the over 80s? Scottish medical journal. 2016;61(3):132-5.

13. Bircan HY, Koc B, Ozcelik U, Adas G, Karahan S, Demirag A. Are there any differences between age groups regarding colorectal surgery in elderly patients? BMC surgery. 2014;14:44.

14. Devon KM, Vergara-Fernandez O, Victor JC, McLeod RS. Colorectal cancer surgery in elderly patients: presentation, treatment, and outcomes. Diseases of the colon and rectum. 2009;52(7):1272-7.

15. Yang Z, Chen H, Liao Y, Xiang J, Kang L, Wang L, et al. Clinicopathological characteristics and longterm outcomes of colorectal cancer in elderly Chinese patients undergoing potentially curative surgery. Surgery today. 2014;44(1):115-22.

16. Nitsche U, Spath C, Muller TC, Maak M, Janssen KP, Wilhelm D, et al. Colorectal cancer surgery remains effective with rising patient age. International journal of colorectal disease. 2014;29(8):9719.

17. Bouassida M, Chtourou MF, Hamzaoui L, Sassi S, Mighri MM, Azzouz MM, et al. Clinico-Pathological Caracteristics, Therapeutic Features and Post-operative Course of Colorectal Cancer in Elderly Patients. Journal of clinical and diagnostic research : JCDR. 2014;8(1):77-9.

18. Morel P, Egeli RA, Wachtl S, Rohner A. Results of operative treatment of gastrointestinal tract tumors in patients over 80 years of age. Archives of surgery (Chicago, III : 1960). 1989;124(6):662-4.

19. Shahir MA, Lemmens VE, van de Poll-Franse LV, Voogd AC, Martijn H, Janssen-Heijnen ML. Elderly patients with rectal cancer have a higher risk of treatment-related complications and a poorer prognosis than younger patients: a population-based study. European journal of cancer (Oxford, England : 1990). 2006;42(17):3015-21.

20. Choo JW, Ju Y, Lim H, Youn SH, Soh JS, Park JW, et al. Is it beneficial to perform surgical resection in elderly patients more than 80 years old with advanced gastric cancer? Scandinavian journal of gastroenterology. 2017;52(10):1057-64.

21. Kristjansson SR, Nesbakken A, Jordhoy MS, Skovlund E, Audisio RA, Johannessen HO, et al. Comprehensive geriatric assessment can predict complications in elderly patients after elective surgery for colorectal cancer: a prospective observational cohort study. Critical reviews in oncology/hematology. 2010;76(3):208-17.

22. Papamichael D, Audisio RA, Glimelius B, de Gramont A, Glynne-Jones R, Haller D, et al. Treatment of colorectal cancer in older patients: International Society of Geriatric Oncology (SIOG) consensus recommendations 2013. Annals of oncology : official journal of the European Society for Medical Oncology. 2015;26(3):463-76. 
Figures

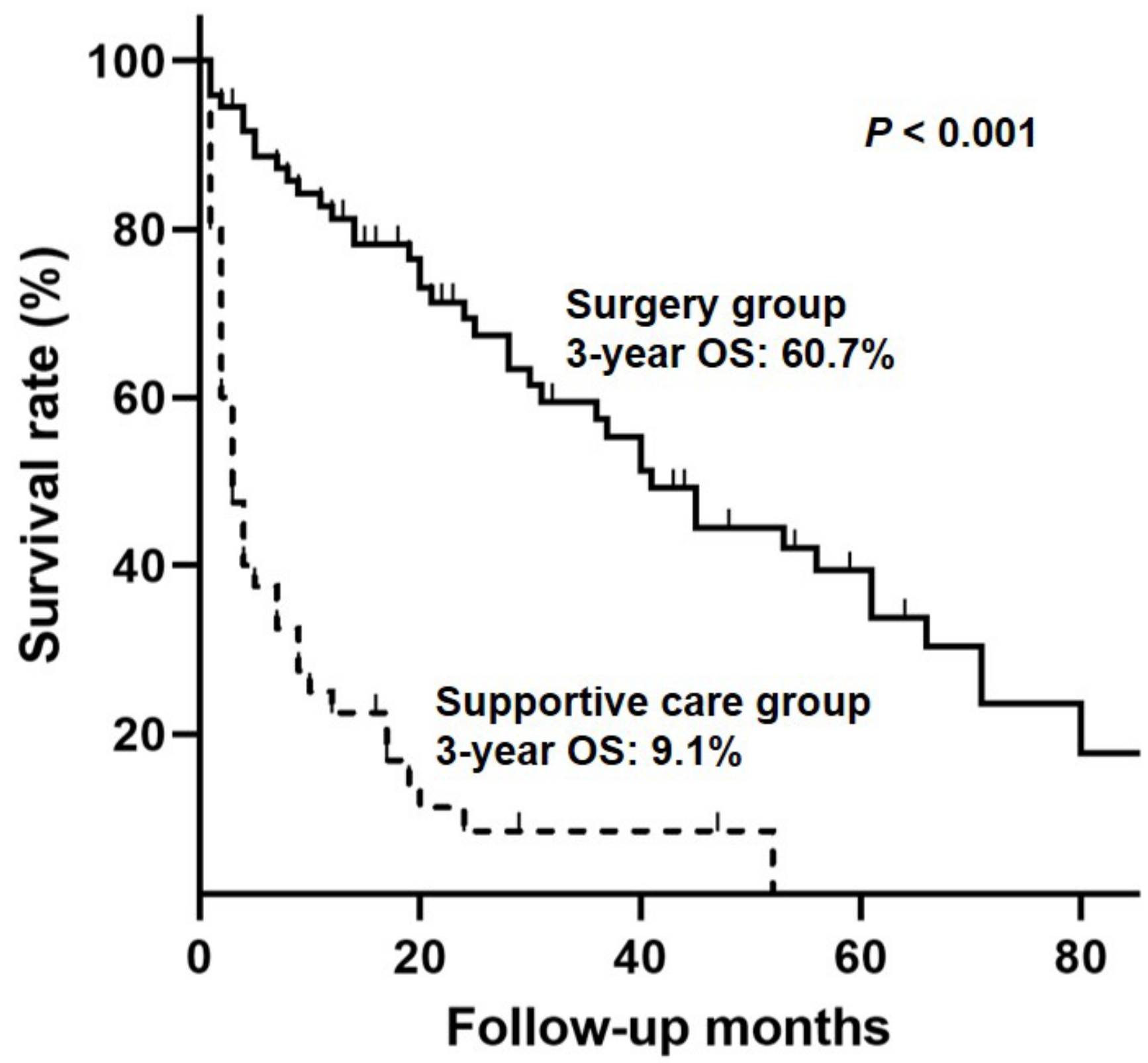

Figure 1

The overall survival curves of the patients according to the treatment modality using Kaplan-Meier estimation 


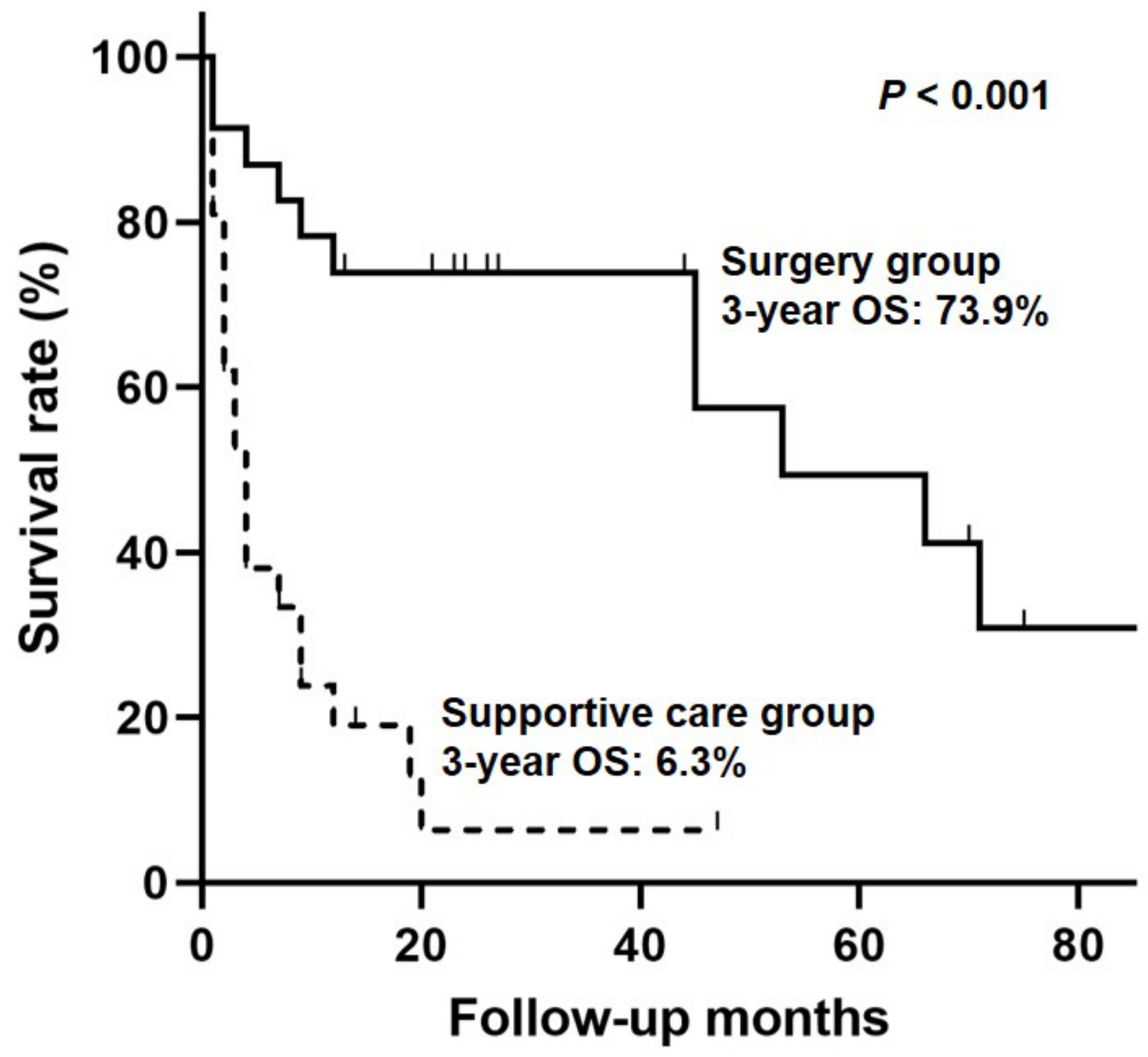

Figure 2

The overall survival curves of the extremely elderly group according to the treatment modality using Kaplan-Meier estimation 